\title{
Selective Effects of Nerve Growth Factor on Spatial Recent Memory as Assessed by a Delayed Nonmatching-to-Position Task in the Water Maze
}

\author{
Alicja L. Markowska, ${ }^{1}$ Donald Price, ${ }^{2}$ and Vassilis E. Koliatsos ${ }^{2}$ \\ ${ }_{1}^{1}$ Neuromnemonics Laboratory, Department of Psychology, The Johns Hopkins University, Ballimore, Maryland 21218, \\ and '2Departments of Neuropathology, Neurology and Neuroscience, The Johns Hopkins University, School of Medicine, \\ Baltimore, Maryland 21205
}

\begin{abstract}
Nerve growth factor (NGF) ameliorates age-related deficits in certain types of memory in rats. Although the effects of NGF on reference memory are well documented, the influence of NGF on recent memory is less well understood. The issue of recent memory is of primary importance in the design of therapies for cognitive disorders, because this type of memory is impaired in elderly humans and is severely affected early in the course of Alzheimer's disease (AD). The present study was designed to evaluate the effects of NGF on recent memory in a task that used escape from water as the motivating stimulus and used the same design as forced-choice recognition tasks given to humans. Fischer-344 rats, 4 months old (4MO) or 23 months old (23MO), were pretested in a new spatial recent memory task designed for the Morris water maze, a delayed nonmatchingto-position task, and infused intraventricularly with recombi-
\end{abstract}

nant human NGF or vehicle. After 2 weeks of NGF infusion, no substantial changes in behavior were observed in either age group. However, NGF treatment extended over 4 weeks improved considerably the choice accuracy of $23 \mathrm{MO}$ rats to a level similar to the performance of $4 \mathrm{MO}$ rats. These results, together with our previous work (Markowska et al., 1994), indicate that the effects of NGF on spatial recent memory are more intense than on spatial reference memory. NGF suppressed the body weight gain in $4 \mathrm{MO}$ rats but did not affect $23 \mathrm{MO}$ rats. In $23 \mathrm{MO}$ rats, NGF mildly counteracted age-related deficits in inhibitory avoidance, but did not have an effect in young rats.

Key words: neurotrophins; NGF; recent memory; working memory; delayed nonmatching-to-position; water maze; aging; Fischer-344
Disturbances in recent memory are a principal concomitant of normal aging in humans (Katzman and Terry, 1983). The preferential failure to encode or retain new information in the face of relatively preserved retrieval of older experiences draws a parallel between age-associated impairments in memory and deficits produced by atrophic and degenerative neuronal changes in medial temporal lobe structures, such as the hippocampal complex, and in the forebrain cholinergic system (Scoville and Milner, 1957; Damasio et al., 1985; Zola-Morgan et al., 1986). Another parallel of the "benign" age-associated deficits is the loss of recent memory in patients with Alzheimer's disease (AD). Although AD patients manifest a wide spectrum of cognitive impairments, loss of recent memory is an early, prominent, and possibly, the most disabling symptom associated with this illness (Bondi ct al., 1994).

Neural substrates critical for the functioning of recent memory (Olton and Papas, 1979; Markowska et al., 1989; Walsh and Chrobak, 1991; Markowska et al., 1995a) involve the connections

\footnotetext{
Received Dec. 18, 1995; revised Feb. 28, 1996; accepted March 3, 1996.

This study was supported by Program Project Grant P5020471. V.E.K. and D.P. have been the Iecipients of the Leadership and Excellence in Alzheimer's Disease Award (NIA AG 07914) and the Javits Neuroscience Investigator Award (National Institutes of Health NS 10580). We thank Dr. L. E. Burton and Genentech for their generous supply of recombinant human NGF, Dr. R. Sukhov for assistance with surgery, Dr. K. Frick for helpful comments on earlier versions of this manuscript, $M$. Barra, O. Ekundayo, M. Markowska, and M. Mooney for assistance with behavioral testing and the preparation of this manuscript. This paper is devoted to the memory of Dr. David S. Olton, an esteemed friend and colleague and a collaborator in the earlier stages of our research.

Correspondence should be addressed to Alicja L. Markowska, Department of Psychology, The Johns Hopkins University, Baltimore, MD 21218.

Copyright (C) 1996 Society for Neuroscience $0270-6474 / 96 / 163541-08 \$ 05.00 / 0$
}

of neurons in the medial septum-diagonal band with the hippocampus (septohippocampal pathway), a significant proportion of which are cholinergic (Frotscher and Leranth, 1985; Wainer et al., 1985; Koliatsos et al., 1990). The cholinergic dependence of recent memory is consistent with the finding that reduction in forebrain cholinergic neurotransmission occurs early in the course of $\mathrm{AD}$ and correlates significantly with cognitive impairments in AD patients (Francis et al., 1994).

Although AD is characterized by disruption of multiple brain pathways (Francis et al., 1994), the vast majority of the available pharmacological approaches to treat this disorder target the cholinergic system of the basal forebrain ('I'hal, 1994). Several strategies have been proposed, ranging from simple enhancement of the cxisting cholincrgic transmission (Thal, 1994) to a structural restoration of the basal forebrain cholinergic system (Scott and Crutcher, 1994). The latter strategy uses trophic (growth) factors, i.e., naturally existing molecules that promote the survival and enhance the differentiation of selected populations of neurons (Phelps et al., 1989; Koliatsos et al., 1993; Olson, 1993; Scott and Crutcher, 1994).

Nerve growth factor (NGF), the founding member of the neurotrophin family of growth factors, is the most potent trophic molecule available for the cholinergic neurons of the basal forebrain (Hefti, 1986; Koliatsos et al., 1991a,b,c; Koliatsos and Price, 1993; Koliatsos et al., 1994). The strongest argument for the use of NGF in the treatment of cholinergic deficits associated with AD comes from studies in aged rodents. Like aged humans and monkeys (Price et al., 1994), these animals also exhibit impairments in memory, which have been found to correlate with a 
decline in forebrain cholinergic neurotransmission (Mandel et al., 1989; Luine and Hearns, 1990; Dunbar et al., 1993). Continuous intraventricular infusion of mouse or human NGF for 4 weeks has been shown to improve reference memory in aged rats (Fischer et al., 1987, 1991; Markowska et al., 1994; Chen et al., 1995).

In the previous studies, special emphasis was given to place discrimination tasks in the water maze as a method to assess spatial reference memory; there was much less interest in the effects of NGF on recent memory. In one study (Markowska et al., 1994), treatment of aged rats with human NGF led to improvements in performance in both recent and reference memory tasks. The effect of NGF on spatial recent memory was more robust than the effect on spatial reference menory, a pattern suggesting that NGF may be more selective for certain types of age-related memory deficits.

In most behavioral tasks, food and water deprivation are used to motivate behavior. With aged animals, such a strategy frequently jeopardizes the health of the animals and results in increased mortality. The use of a recent memory task in the water maze has two advantages: first, it does not require restriction of nutrients. Second, the use of the water maze allows for a more direct comparison with results from place discrimination tasks commonly used in the water maze to assess reference memory. Under these conditions, the type of reinforcement is identical in both tasks.

The present study was designed to examine the selectivity of NGF for spatial recent memory by asking the following questions. First, does NGF improve spatial recent memory in a water maze paradigm that uses escape from water, rather than an appetitive stimulus, for motivation? Second, what is the time course for any improvement in spatial recent memory, and what is the magnitude of this improvement compared with the performance of young rats? Third, are there any effects of NGF on a memory task based on nonspatial cues (i.e., one-trial inhibitory avoidance)? In conjunction with the above three aims, we assessed the body weight of both young and aged rats during the entire course of treatment, because previous observations were based on changes in young rats only and for shorter durations of treatment (Williams, 1991; Lapchak and Hefti, 1992).

\section{MATERIALS AND METHODS}

Subjects. Fischer-344 male rats, 4 months old (4MO) and 23 months old (23MO), were obtained from the NIA colony at Harlan Sprague--Dawley (Indianapolis, IN). Rats were housed (2-3 per cage) in a colony room with a 12:12 light-dark cycle and ad libitum access to food and water. All behavioral testing occurred during the light phase of the light-dark cycle. Body weight was recorded twice a week. After preoperative training in the delayed nonmatching-to-position (DNMTP) procedure, rats underwent surgery for osmotic minipump implantation and chronic NGF or vehicle administration. To counterbalance preoperative performance across two treatment groups, rats within each age category were assigned to one of the NGF or vehicle-control (CON) groups based on their preoperative choice accuracy during the last three DNMTP sessions. Each of the four groups of rats was identified by an abbreviation describing the age (4MO, 23MO) and type of infusion (CON, NGF). The number of rats in each group is in parentheses: 4MO-CON (9), $4 \mathrm{MO}$ NGF (8), 23MO-CON (7), and 23MO-NGF (10).

Surgery. Surgical procedures have been described in detail previously (Markowska ct al., 1994). Bricfly, rats were ancsthetized with a mixture of $33 \% \quad \mathrm{O}_{2}, 66 \% \quad \mathrm{~N}_{2} \mathrm{O}_{2}$, and $2 \%$ enflurane (Ethrane, Ohmeda, Liberty Corner, NJ) via a specially designed nose adaptor attached to a Kopf stereotaxic apparatus. Chloramphenicol $(30 \mathrm{mg} / \mathrm{rat}$, i.p.) was used to prevent infection, with half of the dose delivered before surgery and half immediately after surgery. Under sterile conditions, a cannula was placed into the right or left lateral ventricle. The cannula was connected to an Alzet 2002 osmotic minipump (Alzet Corporation, Palo Alto, CA) and filled with either recombinant human NGF (40 $\mu \mathrm{g}$ of NGF per pump) (Genentech, San Francisco, CA) or with artificial CSF $(210 \mu \mathrm{l} / \mathrm{pump})$. After surgery, each rat was allowed 1 week to recover before behavioral testing. After $14 \mathrm{~d}$, all pumps were replaced with new ones filled with the corresponding NGF or CSF solution.

Experimental design. The timeline for behavioral testing and surgery is illustrated in Figure 1. Briefly, training in DNMTP in the water maze (see Fig. 2) was preceded by two shaping procedures.

For preoperative training in DNMTP (PRE), one session consisting of nine trials was conducted each day for $10 \mathrm{~d}$. Postoperative testing occurred at two different time points during NGF administration. In the second week after surgery (days 10-12), rats were tested only in DNMTP (POST 1). During the fourth week of infusion (POST 2), rats were tested again in DNMTP (days 22-24) and also tested in the inhibitory avoidance (IA) (see Fig. 7) procedure (days 26-27). POST 1 and POST 2 testing procedures in DNMTP were identical to that of PRE testing, except that the shaping procedure was administered only during PRE, and the number of sessions was 3 rather than 10 . The IA was administered only during POST 2.

Data analyses. Statistical analyses were conducted with statistical package SYSTAT 5.03. The following independent variables were included in analyses: age, a comparison between $4 \mathrm{MO}$ rats and 23MO rats; drug, a comparison between type of infusions (NGF or vehicle); group, a comparison among four groups of rats (4MO-CON, 4MO-NGF, 23MO-CON, 23MO-NGF); and time, a comparison between different time points. The values for the latter variable varied depending on the time points taken into analyses, and they were presented as follows: trials, a comparison between trials (i.e., for straight swim); sessions, comparison between sessions (i.e., for preoperative training in DNMTP); weeks, a comparison between means calculated for each week (i.e., for body weight); and periods, a comparison between means calculated for each of three periods of behavioral testing (i.e., PRE, POST 1, and POST 2). The data from straight swim and all dependent measures from DNMTP were analyzed with repeated-measures ANOVA. Because the latency scores for the testing trial of IA were distributed over a broad range of values in all four groups, the between-group differences were analyzed with the nonparametric statistic, Kruskal-Wallis one-way ANOVA.

\section{RESULTS \\ NGF delivery}

In all cases, the inner reservoir of the osmotic pump was found to be collapsed when removed at the end of the experiment. The residual volume left in the pump never exceeded $50 \mu \mathrm{l}$, indicating that all of the solution was delivered. All cannula tubing was clear, and cannula tips were placed successfully in the lateral ventricle. One 4MO-CON rat and one $4 \mathrm{MO}-\mathrm{NGF}$ rat had convulsions at the end of the behavioral training during POST 2, and the data pertinent to these animals were excluded.

\section{Body weight}

The mean body weight \pm SEM was calculated for the week immediately before surgery and for each of the 4 weeks after surgery, separately for each rat. Figure 3 shows the mean body weight of four groups of rats before surgery and during the 4 weeks after surgery. Animal body weight stabilized quickly after surgery and returned to preoperative levels in a few days. A three-way ANOVA (age $\times$ drug $\times$ weeks) revealed a significant effect of age $\left(F_{(1,30)}=42.7, p<0.001\right)$ and a significant effect of weeks $\left(F_{(4,120)}=7.8 ; p<0.001\right)$. Although $23 \mathrm{MO}$ rats had a tendency to lose body weight during the entire period of training, this propensity was not present in $4 \mathrm{MO}$ rats (age $\times$ weeks, $F_{(1,120)}$ $=5.9 ; p<0.001)$. Interestingly, the age $\times$ drug $\times$ weeks interaction $\left(F_{(4,120)}=3.6 ; p<0.01\right)$ was significant, indicating that the tendency toward body weight changes in the two $4 \mathrm{MO}$ groups of rats differed according to treatment condition; $4 \mathrm{MO}-\mathrm{CON}$ rats gained some weight in postoperative weeks 3 and 4, whereas the weight of $4 \mathrm{MO}-\mathrm{NGF}$ rats remained relatively stable. A focused 
PREOPERATIVE
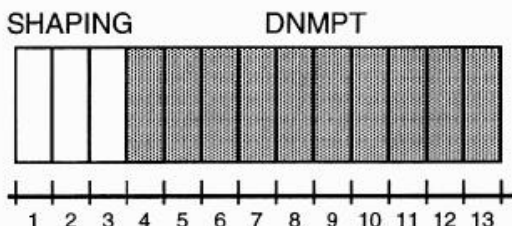

PRE

$\begin{array}{lllllllllllll}1 & 2 & 3 & 4 & 5 & 6 & 7 & 8 & 9 & 10 & 11 & 12 & 13\end{array}$

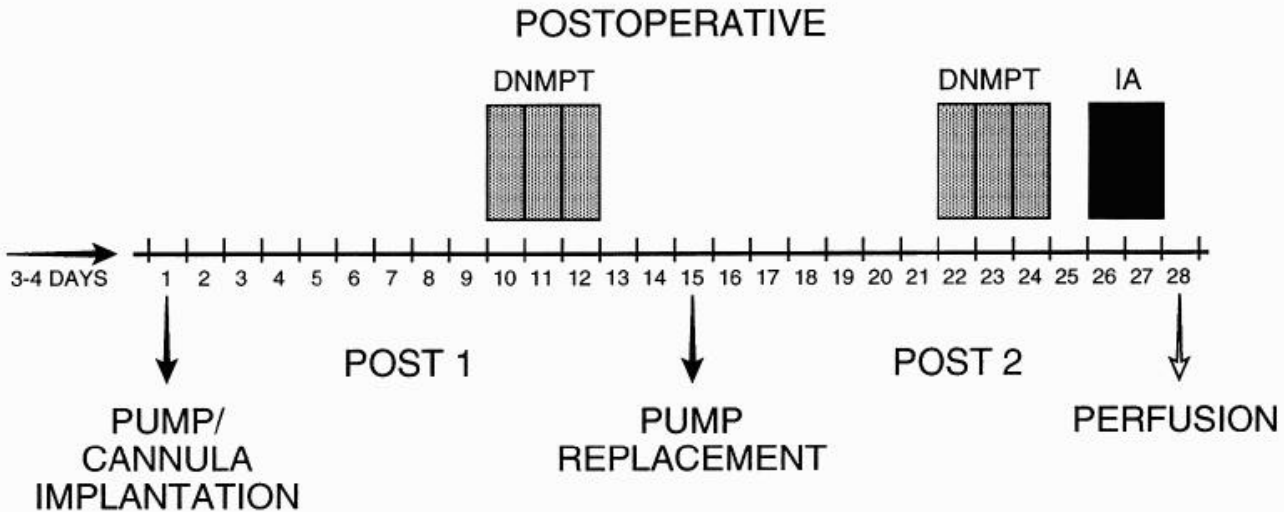

Figure 1. Time line and experimental design. Rats were trained preoperatively. After pump implantation, animals were tested twice in the DNMTP between day 10 and day 13 (POST 1) and between day 22 and day 24 (POST 2). Testing in IA was conducted only during POST 2 between day 26 and day 27. Because Alzet 2002 minipumps are functional only for $14 \mathrm{~d}$, pumps were replaced on day 15 . Animals were killed, and brains were processed for morphometric analyses after $28 \mathrm{~d}$ of continuous infusion.

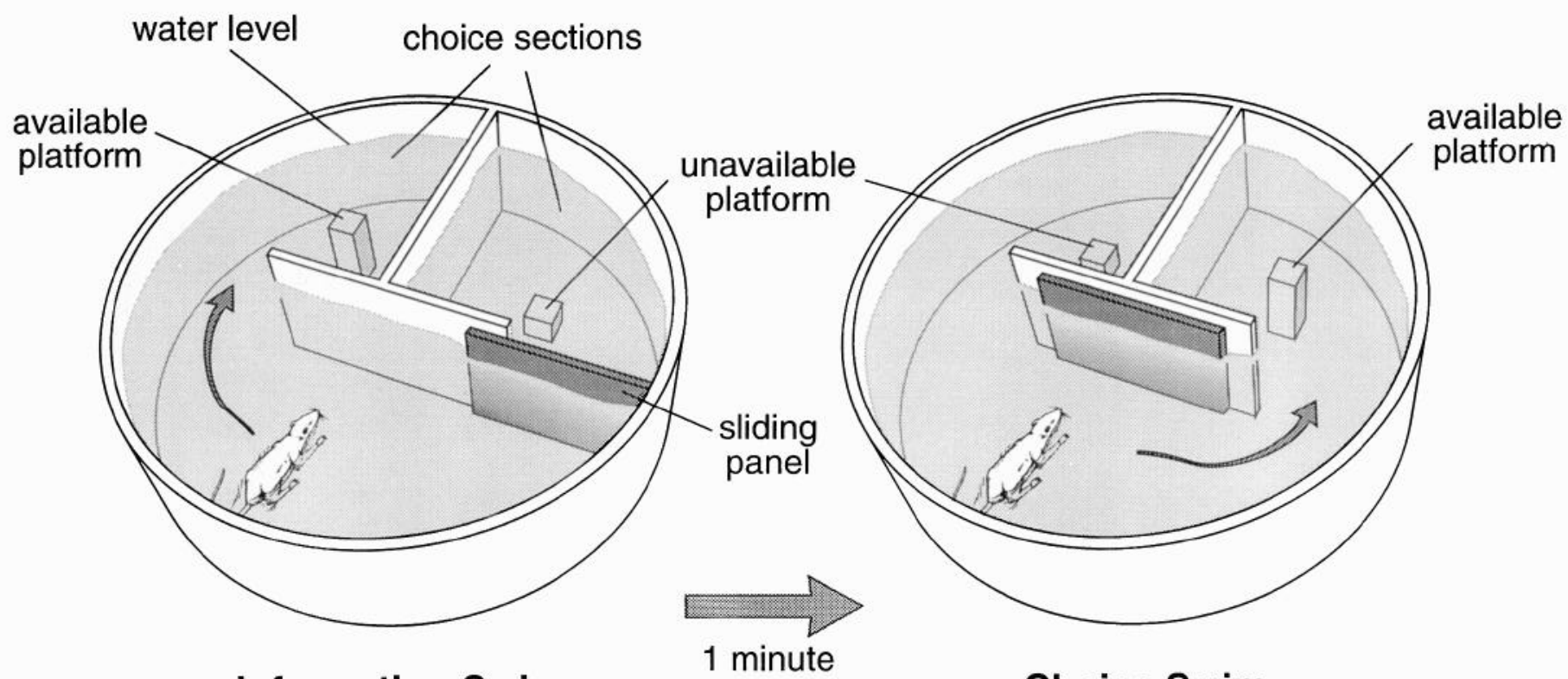

Information Swim

\section{Choice Swim}

Figure 2. Schematic diagram illustrating the DNMTP testing apparatus and procedure. A Plexiglas T-shaped partition was inserted in the water tank (1.8 $\mathrm{m}$ in diameter) to create a start section and two choice sections. A sliding panel either remained centered, allowing access to both choice sections, or was moved to one side to block one section. A collapsible escape platform $\left(10 \mathrm{~cm}^{2}\right)$ was located in each one of the two choice sections. In the raised position, the top of the escape platform was $1 \mathrm{~cm}$ below the surface of the water, and in the lowered position, the top of the platform was $19 \mathrm{~cm}$ below the surface of the water. Only one platform was available (raised position) for the rat for each trial. To train the rat to swim and climb onto the platform, a straight swim procedure (one session, 10 trials) was conducted (for review, see Markowska et al., 1992). A second shaping procedure, using the "T" partition, trains the rat to swim to the platform located in either choice section of the water maze ( 2 consecutive d, nine trials/d), with starting point at the entrance to the choice section (day 1) or in the start section (day 2). For training, each trial consisted of two parts: an Information Swim (IS) and a Choice Swim (CS). For IS, one choice section was open; the platform was located in the open section in its raised position. The rat was allowed $60 \mathrm{sec}$ to locate the platform. After $10 \mathrm{sec}$ on the platform, the rat was placed in a holding cage for $1 \mathrm{~min}$. For the CS, both choice sections were open, but only the platform in the section that was closed previously was available to the rat. If the rat entered the incorrect section, the sliding door was closed, confining the rat for 30 sec. After punishment, the sliding door was opened, and the rat was allowed to locate the platform in the correct section. One session consisted of nine trials (intertrial interval was $\sim 10 \mathrm{~min}$ ).

ANOVA used separately for $4 \mathrm{MO}$ rats showed a significant drug $\times$ weeks interaction $\left(F_{(4,60)}=3.6 ; p<0.01\right)$, supporting the previous conclusion that NGF prevents weight gain in $4 \mathrm{MO}$ rats, and in addition, that this effect was more pronounced in postoperative weeks 3 and $4(p<0.01)$. A focused ANOVA for $23 \mathrm{MO}$ rats revealed that although both groups were losing weight during the experiment $\left(F_{(4,60)}=14.7, p<0.001\right)$, most likely attributable to the physical exercises introduced during behavioral testing,
NGF infusion did not decrease body weight further (effect of drug, drug $\times$ weeks interaction; $p>0.5$ ).

\section{Preoperative performance}

\section{Straight swim}

The $4 \mathrm{MO}$ and $23 \mathrm{MO}$ rats spent more time to reach the platform at the beginning of shaping than at the end of shaping, indicating that the performance improved in both groups (effect of trial; 


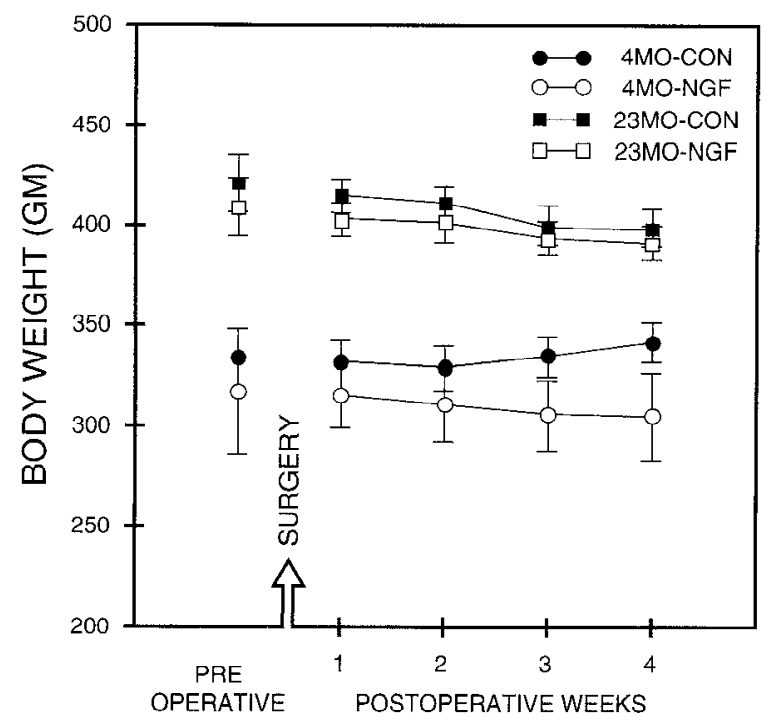

Figure 3. For each group, the mean body weight before surgery (PRE) and during the 4 weeks after surgery is presented. NGF infusion did not change the body weight of $23 \mathrm{MO}$ rats. Both $23 \mathrm{MO}$ groups showed decreased body weight during the 4 postoperative weeks, and this decrease was equal in both groups. $4 \mathrm{MO}-\mathrm{CON}$ rats gained body weight in weeks 3 and 4, whereas 4MO-NGF rats showed a slight nonsignificant decline. Each point represents the mean body weight $( \pm$ SEM) for each group for each week of testing.

$\left.F_{(5,160)}=8.2 ; p<0.001\right)$. At the end of training, latency to reach platform was similar for both groups $(p>0.1)$.

\section{DNMTP}

For analyses of preoperative performance in DNMTP, repeatedmeasures ANOVA (age $\times$ session) was performed on sessions 1-10 separately for each of the three dependent variables: choice accuracy, time for information swim (IS), and time for correct choice swim (CS). For time for incorrect CS, the average for each block of two sessions (instead of single session) was submitted to ANOVA to avoid missing data points.

\section{Choice accuracy}

The $4 \mathrm{MO}$ rats learned quickly and performed accurately (Fig.4). During the last three sessions, mean choice accuracy was $80.7 \pm$ $3.5 \%$.

Aging impaired performance (effect of age; $F_{(1,32)}=12.1 ; p<$ 0.001 ). Although choice accuracy improved during testing (effect of session; $\left.F_{(9,288)}=13.9, p<0.001\right)$, the magnitude of this improvement was not as great in $23 \mathrm{MO}$ as in $4 \mathrm{MO}$ rats (age $\times 10$ sessions; $\left.F_{(9,288)}=2.6, p<0.01\right)$. Although both groups began with a similar level of performance (close to the chance level of $50 \%$ ), by the end of training, choice accuracy was significantly lower in the $23 \mathrm{MO}$ rats than in the $4 \mathrm{MO}$ rats.

\section{Swim time for IS}

Aging increased mean swim time (effect of age; $F_{(1,34)}=24.1 ; p<$ 0.001 ). At the beginning of training (session 1 ), $4 \mathrm{MO}$ rats needed $19.2 \pm 2.9 \mathrm{sec}$ to find the platform, whereas $23 \mathrm{MO}$ took $31.2 \pm 2.9$ sec. The swim time of both groups decreased steadily as the number of sessions increased (effect of session, $F_{(9,288)}=36.4 ; p$ $<0.001)$. The magnitude of this decrease was greater in $23 \mathrm{MO}$ rats than in $4 \mathrm{MO}$ rats (age $\times$ sessions; $F_{(9,288)}=2.5 ; p<0.01$ ). However, at the end of training, the swim time was still longer for

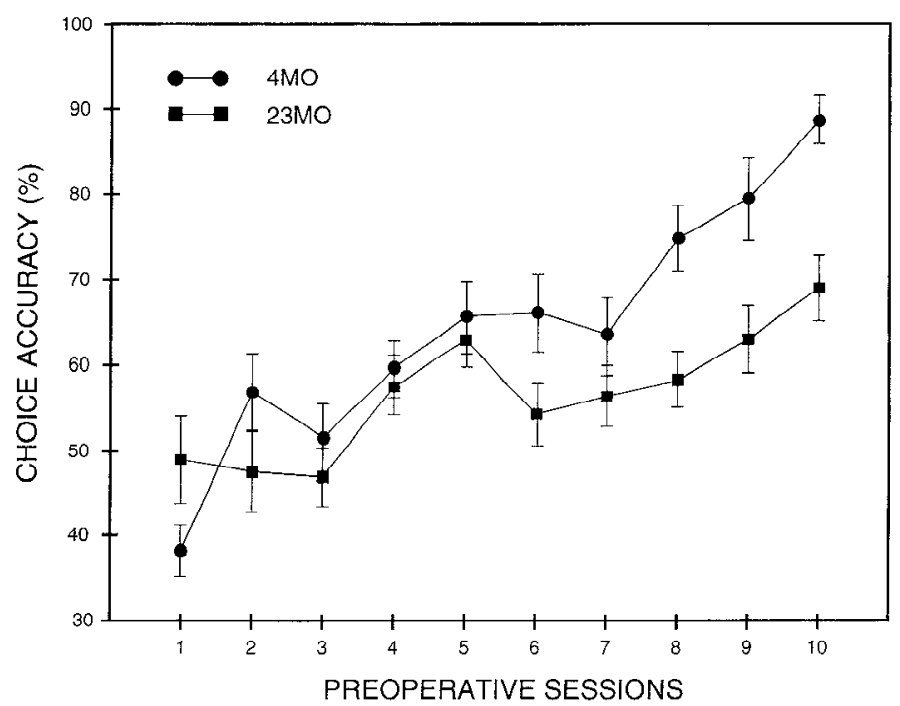

Figure 4. Preoperative DNMTP in the water maze. Preoperative acquisition of the task was slower in $23 \mathrm{MO}$ rats compared with $4 \mathrm{MO}$ rats. The mean choice accuracy of the $4 \mathrm{MO}$ (circles) and the $23 \mathrm{MO}$ (squares) group is presented during 10 preoperative sessions. Each point represents the mean choice accuracy ( \pm SEM) for each group for each session of preoperative testing.

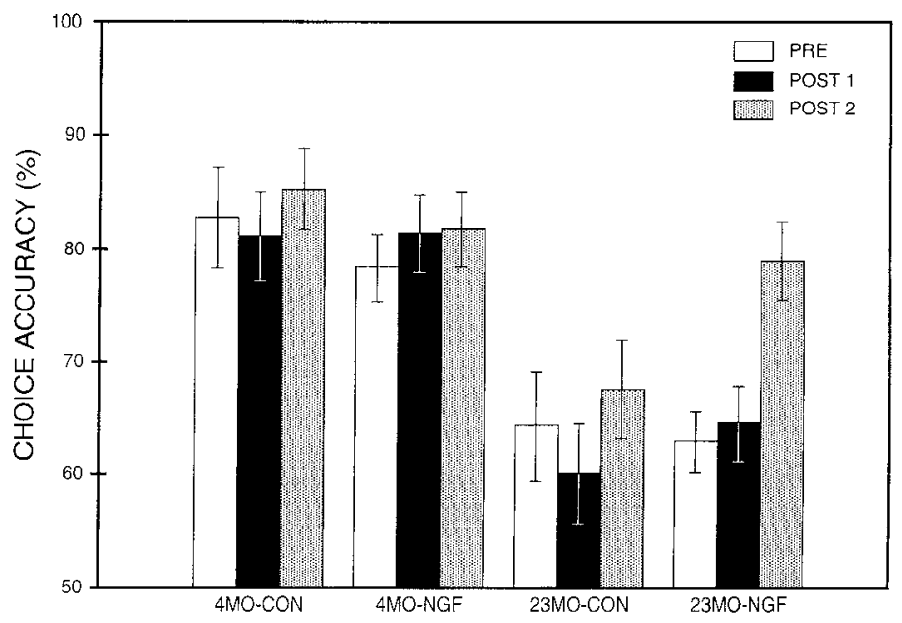

Figure 5. Comparison of mean DNMTP choice accuracy during the preoperative training (PRE), and 2 weeks (POST 1 ) and 4 weeks (POST 2) after the beginning of the infusion. For each group, the mean value $( \pm$ SEM) from PRE, POST 1, and POST 2 is presented. The 23MO-NGF rats improved continuously during POST 1 and POST 2, showing the greatest improvement during POST 2, a period in which they approached the level of $4 \mathrm{MO}-\mathrm{CON}$ rats. The $23 \mathrm{MO}-\mathrm{CON}$ rats showed no significant change in choice accuracy during any of the testing periods. Choice accuracy of $4 \mathrm{MO}-\mathrm{CON}$ and $4 \mathrm{MO}-\mathrm{NGF}$ rats in POST 1 and POST 2 remained the same as in PRE.

$23 \mathrm{MO}$ rats $(10.3 \pm 1.5 \mathrm{sec})$ than for $4 \mathrm{MO}$ rats $(4.7 \pm 1.5$; session $10 ; p<0.05)$.

\section{Swim time for correct $C S$}

The swim time of $23 \mathrm{MO}$ rats was longer than that of $4 \mathrm{MO}$ rats $\left(F_{(1,32)}=10.8 ; p<0.005\right)$. During session $1,4 \mathrm{MO}$ rats spent 14.7 $\pm 2.9 \mathrm{sec}$ to find the platform, whereas $23 \mathrm{MO}$ rats took $20.5 \pm 3.0$ sec. The swim time of both groups decreased steadily over repeated sessions (effect of session; $F_{(9,288)}=17.2, p<0.001$ ). By session 10, the difference between groups was not significant $(p>$ 
$0.2)$; swim time for the $4 \mathrm{MO}$ group was $4.0 \pm 1.5 \mathrm{sec}$ and for the $23 \mathrm{MO}$ group was $7.0 \pm 2.5 \mathrm{sec}$.

\section{Swim time for incorrect $C S$}

Swim time generally was longer during incorrect CS as compared with correct $\mathrm{CS}$, and ranged from $25.4 \pm 2.5$ for $4 \mathrm{MO}$ to $36.9 \pm$ 2.3 for $23 \mathrm{MO}$ in the first block of two sessions. The difference between $23 \mathrm{MO}$ and $4 \mathrm{MO}$ rats was significant across sessions $\left(F_{(1,32)}=28.2, p<0.001\right)$. Swim time decreased in both groups with continued training (effect of session, $F_{(y, 28 \times)}=17.2, p<$ $0.001)$. The difference between groups remained significant until the end of training $(p<0.05)$.

\section{Postoperative performance DNMTP}

For analyses of postoperative performance in DNMTP, repeatedmeasures ANOVA (group $\times$ period) comparing PRE performance with POST 1 and POST 2 used the mean of three sessions within each testing period (for PRE, session 8-10) and was conducted separately for each dependent measure. Two rats did not complete all testing, resulting in fewer degrees of freedom in the POST 2 analyses.

\section{Choice accuracy}

The overall ANOVA (group $\times$ period) revealed a significant effect of groups $\left(F_{(3,28)}=9.3 ; p<0.001\right)$, primarily attributable to a significant effect of age. Choice accuracy varied depending on the period tested (effect of period, $F_{(2,50)}=4.5 ; p<0.02$ ). Additional post hoc analyses showed that $4 \mathrm{MO}-\mathrm{CON}$ and $4 \mathrm{MO}-$ NGF rats did not differ significantly between PRE and POST periods of testing $(p>0.5)$. The choice accuracy of the $23 \mathrm{MO}-$ CON was lower than that of the $4 \mathrm{MO}-\mathrm{CON}$ in all three testing periods: PRE, POST 1, and POST $2(0.005<p<0.01)$.

$A$ robust effect of NGF was observed in aged rats (Figure 5). In the 23MO-NGF group, focused ANOVA revealed significant differences among periods of testing $\left(F_{(2,18)}=8.3 ; p<0.003\right)$. These significant differences were primarily attributable to differences between PRE and POST $2(p<0.01)$ and differences between POST 1 and POST $2(p<0.005)$. The choice accuracy of 23MO-NGF rats was improved significantly after 4 weeks of infusion (i.e., POST 2 compared with PRE level). There were no differences in choice accuracy between PRE and POST 1, demonstrating that NGF did not produce a significant effect on choice accuracy after 2 weeks of infusion (i.e., in POSI 1). Comparison of the performance of the $4 \mathrm{MO}-\mathrm{CON}$ rats with that of $23 \mathrm{MO}-$ NGF rats revealcd that choice accuracy of these two groups was considerably different during PRE $(p<0.003)$ and during POST $1(p<0.01)$. However, the difference in choice accuracy between these two groups was no longer significant during POST 2 ( $p>$ 0.2 ), indicating that the age-related impairment in the $23 \mathrm{MO}$ rats was reversed completely after a 4 week infusion of NGF. In the 23MO-CON group, the choice accuracy during PRE training did not differ significantly from either POST 1 or POST 2 periods ( $p$ $>0.5)$.

Figure 6 represents the percentage of rats in each group during POST 2 whose performance was improved, impaired, or remained the same. None of the $4 \mathrm{MO}-\mathrm{CON}$ rats were impaired in postoperative performance, and only $10 \%$ of $4 \mathrm{MO}-\mathrm{CON}$ rats were improved. The POST 2 performance of the remaining $4 \mathrm{MO}-\mathrm{CON}$ rats and all $4 \mathrm{MO}-\mathrm{NGF}$ rats was the same as during the PRE period. In the $23 \mathrm{MO}-\mathrm{CON}$ group, $10 \%$ of rats were impaired and

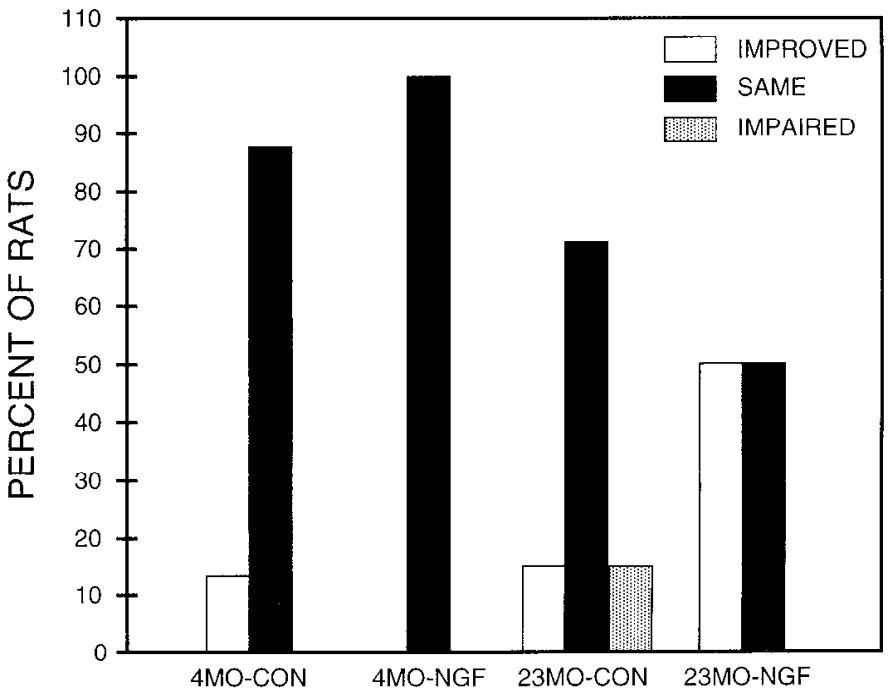

Figure 6. To evaluate the effect of treatment not only on a group level but also on an individual level, the same method typically used to report human data was used (the individual postoperative performance of each rat was classified relative to its own preoperative level). A comparison of POST 2 performance to PRE performance placed cach rat into one of three categories based on the difference between mean postoperative performance and mean preoperative performance: improved (POST 2 better than 2 SEM from PRE), unchanged (POST 2 and PRE within 2 SEM), or impaired (POST 2 worse than 2 SEM from PRE). For each of the four groups, the height of the bar indicates the percentage of rats that were improved (left bar), same (middle bar), and impaired (right bar).

$10 \%$ were improved. NGF in aged rats improved choice accuracy in $50 \%$ of the rats, and none of rats were impaired.

\section{Swim time for IS}

The overall ANOVA (group $\times$ period) revealed a significant effect of groups $\left(F_{(3,30)}=8.0 ; p<0.001\right)$, printarily attributable to a significant effect of age during PRE period (group $\times$ period; $\left.F_{(0,00)}=2.9, p<0.02\right)$. There were no differences between periods of testing in either the $4 \mathrm{MO}-\mathrm{CON}$ or the $4 \mathrm{MO}-\mathrm{NGF}$ group. Although the performance of the 23MO-CON and the 23MO-NGF rats differed during PRE, this difference was no longer significant in POST 1 and POST 2 because of decreased swim time in the $23 \mathrm{MO}-\mathrm{NGF}$. This decrease in swim time was significant only in POST $2(p<0.05)$.

\section{Swim time for correct $C S$}

The swim time of $4 \mathrm{MO}-\mathrm{CON}$ and $4 \mathrm{MO}-\mathrm{NGF}$ rats did not differ among periods of testing $(p>0.5)$. This analogous effect was present in the $23 \mathrm{MO}$ group, indicating that NGF did not produce changes in swim time $(p>0.5)$.

\section{Swim time for incorrect $C S$}

NGF did not produce changes in swim time in either the $4 \mathrm{MO}$ rats or the $23 \mathrm{MO}$ rats $(p>0.5)$. The $4 \mathrm{MO}-\mathrm{CON}$ and $23 \mathrm{MO}-\mathrm{CON}$ rats did not differ among periods of testing $(p>0.5)$.

\section{IA}

Latency scores for retention of IA were distributed over a broad range of values in all four groups. The range of differences between testing and training scores was 35-596 sec for 4MOCON, 68-592 sec for 4MO-NGF, 8-597 sec in 23MO-CON rats, and $25-597 \mathrm{sec}$ in $23 \mathrm{MO}-\mathrm{NGF}$ rats. As shown in Figure 7, 4MONGF rats were not different from $4 \mathrm{MO}-\mathrm{CON}$ rats. The $23 \mathrm{MO}-$ 


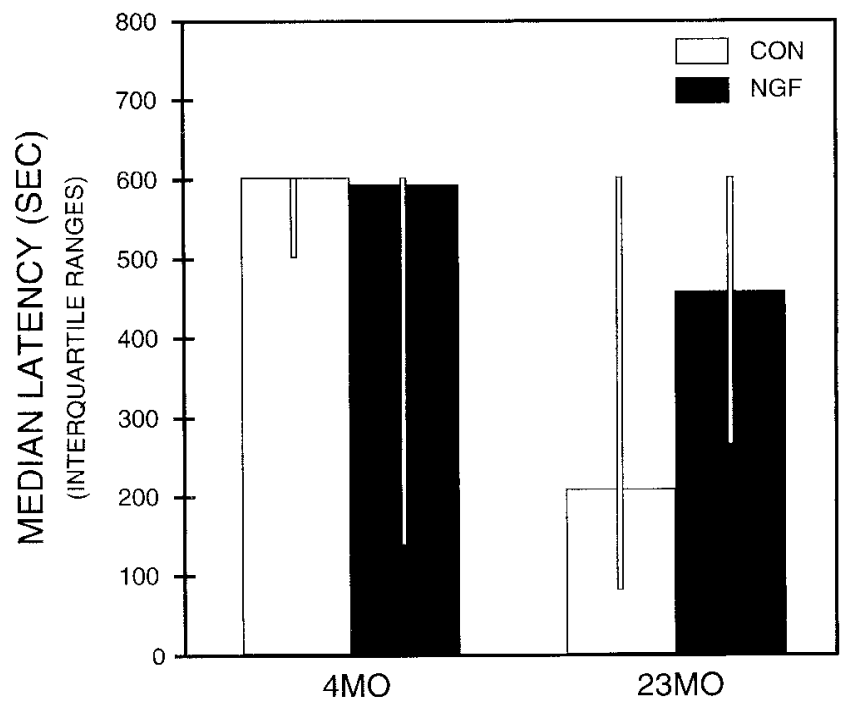

Figure 7. IA. The training apparatus was a two-compartment, rectangular acrylic chamber. A start compartment $(10 \times 14 \times 23 \mathrm{~cm})$ was painted white, illuminated with a lamp $(25 \mathrm{~W})$, and separated from a larger dark compartment $(10 \times 14 \times 37 \mathrm{~cm})$ by a sliding white door. The floor of the apparatus was composed of stainless steel plates that delivered a foot shock $(0.7 \mathrm{~mA}, 1 \mathrm{sec})$ generated by a master shocker. For the training trial, each rat was placed in the start compartment, the sliding door opened, and the rat allowed to enter the dark compartment (all four paws inside). After a brief foot shock $(0.7 \mathrm{~mA}, 1 \mathrm{sec})$ was delivered through the floor, the rat was removed immediately from the chamber. For the testing trial $24 \mathrm{hr}$ later, the rat was returned to the start box, the sliding door opened, and the rat allowed to reenter the dark compartment. A higher value for the latency to enter the dark compartment during the testing trial reflected better retention. Aging resulted in a nonsignificant decrease in retention latencies, but NGF treatment caused a nonsignificant increase in retention latencies, which was intermediate between those of $23 \mathrm{MO}-\mathrm{CON}$ and $4 \mathrm{MO}-\mathrm{CON}$ groups. Vertical lines indicate interquartile ranges.

CON rats had retention latencies lower than those of $4 \mathrm{MO}-\mathrm{CON}$ rats. Furthermore, $23 \mathrm{MO}-\mathrm{NGF}$ rats tended to have longer latencies than 23MO-CON rats. None of the trends in latencies nor in the retention scores reached statistical significance.

\section{DISCUSSION}

\section{NGF and spatial recent memory}

The results from the present experiment demonstrate that human NGF, administered via a ventricular osmotic minipump, ameliorates age-related decline in spatial recent memory in $23 \mathrm{MO}$ Fischer-344 rats, as assessed by a novel DNMTP task in the water maze. This improvement reached a level of choice accuracy equivalent to that observed in the $4 \mathrm{MO}$ rats. The fact that NGF infusion did not significantly affect swim time during the CS of either group of rats indicates that the improved choice accuracy in aged rats was not the result of improved swimming ability, but more likely a consequence of improved memory. This result is consistent with our previous finding that NGF does not influence sensorimotor performance of rats (Markowska et al., 1994).

In comparison with our previous finding, the Morris water maze procedure in the current study, adopted to resemble a T-maze spatial alternation (so that working memory and reference memory could be compared under identical conditions), confirm the superior effects of NGF on working memory compared with reference memory. The selectivity of NGF for recent memory has important implications for the treatment of AD, an illness in which loss of recent memory manifested in its early stages is a major cause of morbidity. These results provide valuable information about the effects of NGF on recent memory, an aspect of NGF pharmacology for which there is very little information (Markowska et al., 1994). In light of the evidence that loss of recent memory is the most prominent cognitive deficit in elderly humans and in the early stages of AD, the beneficial effects of NGF therapy on this type of memory are bound to have substantial clinical significance.

\section{Complete or partial reversal of age-related changes in recent memory versus reference memory: effect of doses}

Age-related deficits in recent memory as observed in DNMTP were reversed completely by NGF. Previous studies using smaller doses $(10 \mu \mathrm{g} /$ week) (Markowska et al., 1994) or much lower doses (1.1-2.1 $\mu \mathrm{g} /$ week) (Fischer et al., 1987, 1991; Chen et al., 1995) of NGF reported only a partial reversal of deficits in reference memory as assessed by a place discrimination task in the water maze. The effects of NGF on reference memory were much milder, resulting in performance at an intermediate level between old and young rats (Fischer, 1987, 1991; Markowska et al., 1994; Chen et al., 1995). These behavioral effects werc accompanicd by a partial reversal of the cholinergic cell atrophy in the basal forebrain (Fischer et al., 1987, 1991; Markowska et al., 1995b).

Higher doses of NGF (40-42 $\mu \mathrm{g} /$ week) resulted in either a partial reversal (Markowska et al., 1994) or a complete reversal of reference memory deficits (Fischer, 1994), suggesting that dose dependence is not the only factor contributing to the magnitude of the reversal. Because these experiments were conducted on 23MO Fischer-344 male rats (Markowska et al., 1994) or aged Sprague-Dawley female rats (Fischer, 1994), perhaps the strain or gender of the rats plays an important role in their vulnerability to NGF treatment. These issues need additional consideration. Conversely, doses of NGF $(8.4 \mu \mathrm{g} /$ week $)$ smaller than the doses successful in the complete reversal of behavioral deficits have been reported to reverse some age-associated structural alterations in dendritic spines of neocortical neurons to a level similar to that observed in young controls (Mervis et al., 1991). Although these effects need to be studied further and their nature and mechanisms better understood, they suggest that the duration and doses of NGF treatment are parameters of equal importance to the susceptibility of subjects (strain, gender, and possibly chronological age) in mediating therapeutic effects in the mammalian forebrain.

\section{Effect of NGF on different paradigms of recent memory}

The NGF effects on choicc accuracy of old rats reported in the present study are consistent with previous findings obtained in a different behavioral paradigm, i.e., spatial delayed alternation in the T-maze (Markowska et al., 1994). In both behavioral tasks, which assess recent memory, NGF improved choice accuracy. Interestingly, the magnitude of improvement by NGF differed in the two studies. There was a complete reversal of age-related decline in DNMTP (present study), but only a partial reversal in spatial delayed alternation (our previous study). This discrepancy may have resulted from differences in the type of the task used to assess recent memory. Although both tasks were based on forcedchoice recognition, the type of reinforcement differed between the two (i.e., appetitive reinforcement was used in spatial delayed alternation, and aversive reinforcement was implemented in DNMTP). The food and water intake restrictions used in our previous study were eliminated in the present experiments to 
avoid the potential contribution of NGF-induced anorexia (Williams et al., 1991). Because the dose of NGF (20 $\mu \mathrm{g} / \mathrm{week})$ used in the present study was within the range of doses used in our previous study ( $40 \mu \mathrm{g} /$ week and $10 \mu \mathrm{g} /$ week) and still induced a relatively stronger effect, it is likely that the difference in reinforcement rather than the NGF dose contributed to the magnitude of the NGF effect.

\section{Time course of NGF effect on behavior}

In the present study, 2 weeks of continuous infusion of NGF did not affect the choice accuracy in $23 \mathrm{MO}$ rats. However, extension of NGF treatment to 4 weeks resulted in substantial improvements in the above measure. Consistent with the results of the present study, delayed effects of NGF have been observed in reference memory using both lower (1.1-2.1 $\mu \mathrm{g} / \mathrm{week}$ ) (Fischer et al., 1987; Chen et al., 1995) and higher (42 $\mu \mathrm{g} / \mathrm{week}$ ) (Fischer, 1994) doses of NGF. However, ChAT activity has been shown to be stimulated only after 2 weeks of NGF treatment, cven with lower doses of the peptide (Vantini et al., 1990; Hefti and Lapchak, 1993; Koliatsos et al., 1994), and an increase in ChATimmunoreactive varicosities, in size of cholinergic boutons and in the number of synaptic contacts, was reported after $7 \mathrm{~d}$ of NGF infusion (Garofalo et al., 1992). In light of the above neurobiological findings, the delayed effects of NGF on the behavior of aged rats suggest that changes in the cholinergic system precede improvements in memory by $\sim 2-3$ weeks.

\section{NGF effects on young rats}

Neither 2 nor 4 weeks of NGF infusion significantly affected spatial recent memory in young rats. However, choice accuracy in the 4MO-NGF group was slightly, but not significantly, decreased relative to the $4 \mathrm{MO}-\mathrm{CON}$ group during NGF infusion. The choice accuracy of $10 \%$ of the $4 \mathrm{MO}-\mathrm{CON}$ group rats improved with training, whereas the choice accuracy of the 4MO-NGF rats was unchanged. The direction of this difference (lower choice accuracy in $4 \mathrm{MO}-\mathrm{CON}$ rats than in $4 \mathrm{MO}-\mathrm{NGF}$ rats during POST 2) is consistent with a previous study (Markowska et al., 1994). However, in a T-maze delayed alternation task, the magnitude of this difference was significantly greater. This discrepancy in the magnitude of NGF effects on young rats' performance between these two studies may be attributable to the type of paradigm used and the type of motivation implemented for the performance of the task. Given the suppression of weight gain induced by NGF, perhaps choice accuracy in the T-maze was affected by a decreased appetite, which in turn could decrease motivation to perform the task.

\section{NGF and IA}

In addition to its positive effect on spatial memory, NGF may influence nonspatial memory. In the present study, the $23 \mathrm{MO}$ CON group showed a mild deficit in IA tested $24 \mathrm{hr}$ after the training trial; only about $25 \%$ of the sample had latencies near the maximum of $600 \mathrm{sec}$, whereas the remaining rats had much shorter latencies. Other studies have found similar ranges of performance in old rats (Stone et al., 1989). In the 23MO-NGF rats, almost $50 \%$ of the sample had latencies near the maximum of $600 \mathrm{sec}$. However, this effect did not reach statistical significance. These data demonstrate that the dose of NGF (20 $\mu \mathrm{g} / \mathrm{week})$ that effectively improved spatial memory was not sufficient to influence nonspatial memory.

\section{NGF-induced weight loss}

A significant reduction in food consumption and weight gain compared with untreated and vehicle-treated rats occurred after 2 weeks of NGF treatment in young (3-5 months old) SpragueDawley rats (Williams, 1991). Although, the dose of NGF used in the present study was higher than that used in the previous study (20 $\mu \mathrm{g} /$ week and $8.4 \mu \mathrm{g} / \mathrm{week}$, respectively), we did not observe a significant loss of body weight in the first 2 weeks of treatment. Weight differences between $4 \mathrm{MO}-\mathrm{CON}$ rats and $4 \mathrm{MO}-\mathrm{NGF}$ rats that emerged during the third week of NGF infusion and persisted throughout the fourth week were principally caused by a weight gain of animals in the $4 \mathrm{MO}-\mathrm{CON}$ group (compared with lack of weight gain in $4 \mathrm{MO}-\mathrm{NGF}$ animals). In $4 \mathrm{MO}$ rats, a gain in body weight is expected as a concomitant of continuing growth, and the lack of weight gain observed in 4MO-NGF rats implies a contribution from NGF-induced anorexia. Similar NGF-induced (injections of $1.4 \mu \mathrm{g}$ every second day) suppression of weight gain has been observed in young female Wistar rats, in which significant changes in body weight emerged after day 12 of NGF treatment and persisted until the end of the experiment (Lapchak and Hefti, 1992).

Interestingly, the reduction in body weight was nearly identical between $23 \mathrm{MO}-\mathrm{CON}$ and $23 \mathrm{MO}-\mathrm{NGF}$ rats, a pattern suggesting that NGF infusion did not contribute to weight loss in aged rats. In fact, our extensive expcricnce with aged rats (Markowska et al., 1995c) suggests that physical exercise alone as a concomitant of behavioral testing results in weight loss. We therefore assume that the extensive daily training was a major contributor to the weight loss in all $23 \mathrm{MO}$ rats.

Although hypothalamic mechanisms have been postulated (Buck et al., 1988; Oliveira et al., 1990; Pelleymounter et al., 1995), the exact nature of the anorexic effect of centrally delivered neurotrophins in young rats remains unclear. The lack of effect of intraventricular NGF infusion on the body weight of aged animals suggests that the brain targets through which NGF affects appetite suppression may not be intact structurally or responsive in these subjects.

\section{CONCLUSION}

Our findings support the hypothesis that NGF can reverse agerelated deficits in spatial recent memory, the type of memory that undergoes age-associated alteration in rodents as well as in the early stages of $\mathrm{AD}$. Recent evidence that demonstrates a positive correlation between NGF-induced hypertrophy of BFCS cholinergic neurons and improved working memory in aged rats (Markowska et al., 1995b), and a positive correlation between NGF-induced synaptic sprouting in the frontal cortex with place discrimination performance in the water maze (Chen et al., 1995), implies that NGF-induced enhancements in cognitive function in aged rats are the result of changes in the basal forebrain cholinergic system. However, the causal relationship of these effects need to be studied further. The fact that the cholinergic neurons located in the basal forebrain cholinergic system predominantly express trk A receptors, the high-affinity receptor for NGF, may cxplain their high sensitivity to NGF therapy. The capacity of NGF to bolster cholinergic neurons of the BFCS may, in turn, explain the augmented recent memory observed in aged animals. These findings may increase significantly the relevance of NGF as a therapeutic agent for $\mathrm{AD}$, in which loss of recent memory represents one of the earliest and the most debilitating features associated with this dementing disorder.

\section{REFERENCES}

Bondi MW, Salmon DP, Butters N (1994) Neuropsychological features of memory disorders in Alzheimer disease. In: Alzheimer's disease (Terry RD, Katzman R, Bick KL, eds). New York: Raven. 
Buck CR, Martinez HJ, Chao MV, Black IB (1988) Differential expression of the nerve growth factor receptor gene in multiple brain areas. Dev Brain Res 44:259-268.

Chen KS, Masliah E, Mallory M, Gage FH (1995) Synaptic loss in cognitively impaired aged rats is ameliorated by chronic human nerve growth factor infusion. Neuroscience 68:19-27.

Damasio AR, Eslinger PJ, Damasio H, Van Hoesen GW, Cornell S (1985) Multimodal amnesic syndrome following bilateral temporal and basal forebrain damage. Arch Neurol 42:252-259.

Dunbar GL, Rylett RJ, Schmidt BM, Sinclair RC, Williams LR (1993) Hippocampal choline acetyl transferase activity correlates with spatial learning in aged rats. Brain Res 604:266-272.

Fischer W (1994) Nerve growth factor reverses spatial memory impairments in aged rats. Neurochem Int 25:47-52.

Fischer W, Wictorin K, Björklund A, Williams LR, Varon S, Gage FH (1987) Amelioration of cholinergic ncuron atrophy and spatial memory impairment in aged rats by nerve growth factor. Nature 329:65-68.

Fischer W, Björklund A, Chen K, Gage FH (1991) NGF improves spatial memory in aged rodents as a function of age. $\mathbf{J}$ Neurosci 11:1889-1906.

Francis PT, Cross AJ, Bowen DM (1994) Neurotransmitter and neuropeptides. In: Alzheimer disease (Terry RD, Katzman R, Bick KL eds). New York: Raven.

Frotscher M, Leranth C (1985) Cholinergic innervation of the rat hippocampus as revealed by choline acetyl transferase immunocytochemistry: a combined light and electron microscopic study. J Comp Neuro 239:237-246.

Garofalo L, Ribeiro-da-Silva A, Cuello AC (1992) Nerve growth factorinduced synaptogenesis and hypertrophy of cortical cholinergic terminals. Proc Natl Acad Sci USA 89:2639-2643.

Hefti F (1986) Nerve growth factor promotes survival of septal cholinergic neurons after fimbrial transections. J Neurosci 6:2155-2162.

Hefti F, Lapchak PA (1993) Pharmacology of nerve growth factor in the brain. Adv Pharmacol 24:239-273.

Katzman R, Terry RD (1983) Senile dementia of Alzheimer type: defining a disease. In: The neurology of aging (Katzman R, Terry RD, eds), pp 51-84. Philadelphia: FA Davis.

Koliatsos VE, Price DL (1993) Nonhuman primate models in trophic factor research. In: Neuromethods. XXV. Neurotrophic factors (Boulton A, Baker G, Hefti F, eds), pp 331-370. Totowa, NJ: Humana.

Koliatsos VE, Nauta WHJ, Clatterbuck RE, Holtzman DM, Mobley WC, Price DL (1990) Mouse nerve growth factor prevents degeneration of axotomized basal forebrain cholinergic neurons in the monkey. $\mathbf{J}$ Neurosci 10:3801-3813.

Koliatsos VE, Applegate MD, Kunsel B, Junard EO, Burton LE, Mobley WC, Hefti FF, Price DL (1991a) Recombinant human nerve growth factor prevents retrograde degeneration of axotomized basal forebrain cholinergic neurons in the rat. Exp Neurol 112:161-173.

Koliatsos VE, Clatterbuck RE, Gouras GK, Price DL (1991b) Biologic effects of nerve growth factor on lesioned basal forebrain neurons. Ann NY Acad Sci 640:102-109.

Koliatsos VE, Clatterbuck RE, Nauta WHJ, Knusel B, Burton LE, Hefti FF, Mobley WC, Price DL (1991c) Human nerve growth factor prevents degeneration of basal forebrain cholinergic neurons in primates. Ann Neurol 30:831-840.

Koliatsos VE, Price DL, Clatterbuck RE, Markowska AL, Olton DS, Wilcox BJ (1993) Neurotrophic strategies for treating Alzheimer's disease: lessons from basic neurobiology and animal models. Ann NY Acad Sci 695:292-299.

Koliatsos VE, Price DL, Gouras GK, Cayoutte MH, Burton LE, Winslow JW (1994) Highly selective effects of nerve growth factor, brainderived neurotrophic factor, and neurotrophin-3 on intact and injured basal forebrain magnocellular neurons. J Comp Neurol 343:247-262.

Lapchak PA, Hefti F (1992) BDNF and NGF treatment in lesioned rats: effects on cholinergic function and weight gain. NeuroReport 3:405-408.

Luine V, Hearns M (1990) Spatial memory deficits in aged rats: contributions of the cholinergic system assessed by ChAT. Brain Res 523:321-324.

Mandcl RJ, Gagc FH, Thal LJ (1989) Spatial learning in rats: correlation with cortical choline acetyltransferase and improvement with NGF following NBM damage. Exp Neurol 104:208-217.
Markowska AL, Olton DS, Murray EA, Gaffan D (1989) A comparative analysis of the role of fornix and cingulate cortex in memory: rats. Exp Brain Res 74:187-201.

Markowska AL, Koliatsos VE, Breckler SJ, Price DL, Olton DS (1994) Human nerve growth factor improves spatial memory in aged but not in young rats. J Neurosci 14:4815-4824.

Markowska AL, Olton DS, Givens B (1995a) Cholinergic manipulations in the medial septal area: age-related effects on working memory and hippocampal electrophysiology. J Neurosci 15:2063-2073.

Markowska AL, Breckler SJ, Price DL, Koliatsos VE (1995b) Nerve growth factor (NGF) induced hypertrophy of basal forebrain cholinergic neurons ameliorates spatial memory impairment in aged rats, $\mathrm{p} 14$. Amelia Island, FL: Third Suncoast Workshop on the Neurobiology of Aging.

Markowska AL, Barra ME, Breckler SJ, Olton DS (1995c) A longitudinal assessment of memory, sensorimotor skills, blood glucose levels and glucose tolerance in Fischer-344 rats: effects of diet restriction. Soc Neurosci Abstr 21:177.

Mervis RF, Pope D, Lewis R, Dvorak RM, Williams LR (1991) Exogenous nerve growth factor reverses age-related structural changes in neocortical neurons in the aging rat. Ann NY Acad Sci 640:95-101.

Oliveira LA, Gentil CG, Covian MR (1990) Role of the septal area in feeding behavior elicited by electrical stimulation of the lateral hypothalamus of the rat. Braz J Med Biol Res 23:49-58.

Olson L (1993) NGF and the treatment of Alzheimer's disease. Exp Neurol 124:5-15.

Olton DS, Papas BC (1979) Spatial memory and hippocampal function. Neuropsychologia 17:669-682.

Pelleymounter MA, Cullen MJ, Wellman CL (1995) Characteristics of BDNF-induced weight loss. Exp Neurol 131:229-238.

Phelps CH, Gage FH, Growdon JH, Hefti F, Harbaugh R, Johnston V, Khachaturian Z, Mobley W, Price D, Raskind M, Simpkins J, Thal L, Woodcock J (1989) Potential use of nerve growth factor to treal Alzheimer's disease. Neurobiol Aging 10:205-207.

Price DL, Martin LJ, Sisodia SS, Walker LC, Voytko ML, Wagster MV, Cork LC, Koliatsos VE (1994) The aged nonhuman primate: a model for the behavioral and brain abnormalities occurring in aged humans. In: Alzheimer's disease (Terry RD, Katzman R, Bick KI, eds). New York: Raven.

Scott SA, Crutcher KA (1994) Nerve growth factor and Alzheimer's disease. Rev Neurosci 5:179-211.

Scoville WB, Milner B (1957) Loss of recent memory aftcr bilatcral hippocampal lesions. J Neurol Neurosurg Psychiatry 20:11-21.

Stone WS, Altman HJ, Berman RF, Cladwell DF, Kilbey MM (1989) Association of sleep parameters and memory in intact old and nucleus basalis-lesioned young rats. Behav Neurosci 103:755-764.

Thal LJ (1994) Clinical trials in Alzheimer disease. In: Alzheimer's disease (Terry RD, Katzman R, Bick KL, eds). New York: Raven.

Vantini G, Fusco M, Schiavo N, Gradkowska M, Zaremba M, Leon A Oderfeld-Nowak B (1990) Nerve Growth Factor induces a dosedependent and long-lasting increase of choline acetyl transferase activity in the septal area and hippocampus of uninjured rats. Acta Neurobiol Exp 50:323-332.

Wainer JA, Levey AI, Rye DB, Mesulam M-M, Mufson EJ (1985) Cholinergic and non-cholinergic septohippocampal pathways. Neurosci Lett 54:45-52.

Walsh TJ, Chrobak JJ (1991) Animal models of Alzheimer's disease: role of hippocampal cholinergic systems in working memory. In: Current topics in animal learning: brain, evolution, emotion, and cognition (Dachowsky L, Flaherty C, eds), pp 347-378. Trenton, NJ Erlbaum.

Williams LR (1991) Hypophagia is induced by intracerebroventricular administration of nerve growth factor. Exp Neurol 113:31-37.

Williams LR, Rylett JR, Moises HC, Tang AH (1991) Exogenous nerve growth factor affects cholinergic transmitter function and Y-maze behavior in aged Fischer-344 male rats. Can J Neurol Sc 18:403-407.

Zola-Morgan S, Squire LR, Amaral DG (1986) Human amnesia and the medial temporal region: enduring memory impairment following a bilateral lesion limited to field $\mathrm{CA} 1$ of the hippocampus. J Neurosci $6: 2950-2967$. 